\title{
Low Activity Spectrometric Gamma-Gamma Borehole Logging Tool for the Metalliferous Industry
}

\author{
JAmal Asfahani \\ Atomic Energy Commission, \\ Geology Department, Damascus, Syria \\ Received: 26/8/2001 Revised: 28/12/2002 Accepted: 31/12/2002
}

\begin{abstract}
AвSTRACT. The low activity spectrometric gamma-gamma technique was applied to the quantitative determination of lead and zinc grades in boreholes well-logging. The tool was centralized and employed a $\gamma$-ray source of very low activity $(1.8 \mathrm{MBq})$. The log tool was tested separately using (i) ${ }^{133} \mathrm{Ba}$ and (ii) ${ }^{137} \mathrm{Cs}$ with $37 * 75 \mathrm{~mm} \mathrm{NaI}$ (TI) scintillation detector. Five source-detector configurations were studied and analyzed in the present work. The calibration equations for lead $(\mathrm{Pb})$ and Zinc Metal Equivalent (ZME) prediction using Barium and Cesium sources have been quantitatively described for every studied configuration. The optimum configuration for the logging probe using a ${ }^{133} \mathrm{Ba}$ source is determined to be $52 \mathrm{~mm}$ source to detector spacing. This configuration gives the best results for both $\mathrm{Pb}$ and $\mathrm{ZME}$ grade. The r.m.s. deviation for $\mathrm{Pb}$ and $\mathrm{ZME}$ are 0.33 and $2.3 \%$ respectively. The optimum configuration for the logging probe using a ${ }^{137} \mathrm{Cs}$ source is determined to be $64 \mathrm{~mm}$ source to detector spacing. This configuration gives the best results for both $\mathrm{Pb}$ and $\mathrm{ZME}$ grade. The r.m.s. deviation for $\mathrm{Pb}$ and $\mathrm{ZME}$ are 0.36 and $2.2 \%$ respectively. The advantage of using low activity ${ }^{137} \mathrm{Cs}$ source is that this radioactive source does not need an extra source for spectrum gain stabilization, where the same source is used for both primary sources of radiation and gain stabilization. In addition, ${ }^{137} \mathrm{Cs}$ source is characterized by longer half- life and greater penetration effect of its gamma radiation. The low activity ${ }^{133} \mathrm{Ba}$ source however necessitates an additional ${ }^{137} \mathrm{Cs}$ microsource for gain stabilization. The tool is sensitive to changes in Zeq number of the matrix surrounding the borehole and could find application in the metalliferous mining industry for ore body delineation. Due to its very low $\gamma$-ray source activity and lightweight, the tool is ideal for use with portable logging systems and underground mining operations.
\end{abstract}

\section{Introduction}

The delineation of the ore body and determination of $\mathrm{Pb}$ and $\mathrm{Zn}$ concentrations in $\mathrm{Pb}-\mathrm{Zn}$ deposits are important parameters both in the exploration and mine production stages of $\mathrm{Pb}-\mathrm{Zn}$ mine. Prediction of these parameters translates into 
reduced ore dilution. This increases the efficiency of the mine and reduces the operation costs, which can bring substantial financial saving to the mining company. The backscattered $\gamma$-technique is very well established in borehole logging in coal mining industry. Most of the commercial logging companies use the nonspectrometric $\gamma-\gamma$ technique, which is adequate for density measurements of delineation of coal seams. However, the non-spectrometric $\gamma-\gamma$ is not suitable for quantitative ore grade measurements. The more sophisticated technique $\gamma-\gamma$ is spectrometric. It records the whole backscattered spectrum after each logging interval. The spectra are saved in a computer and processed at the end of logging.

Researches have been carried out in the last few years to develop spectrometric $\gamma-\gamma$ technique for borehole logging, using very low activity sources. The availability of borehole logging equipment, using sources of activity lower than 3.7 MBq but capable of quantitative analysis, provides minimal risk to safety and environmental integrity. The fact that such systems do not require heavy shielding for the radioactive source makes them suitable to be portable logging systems, which are easier to be used in underground mining operations and do not require a dedicated logging vehicle. A nuclear well-logging, based on spectrometric backscattered $\gamma-\gamma$ using low radioactivity source, has been applied in coal and iron mining (Charbucinski, 1993; Borsaru and Ceravolo, 1994; Borsaru et al., 1995; Charbucinski et al.,1996). There are more applications for this technique in the metalliferous mining industry for ore body delineation (Charbucinski et al., 1997; Asfahani, 1999). The present work deals with the laboratory investigation of the application of the backscattered technique $\gamma-\gamma$ to the in site determination of $\mathrm{Pb}$ concentration in boreholes as $\mathrm{Pb}-\mathrm{Zn}$ deposit.

The aim of this research work is to compare the achieved sensitivity and accuracy of Barium source with those obtained for the tool utilizing Cesium microsource. It was anticipated that lower energy ${ }^{133} \mathrm{Ba}$ source should provide better sensitivity for $\mathrm{ZME}$ and $\mathrm{Pb}$ grade determination than the applied ${ }^{137} \mathrm{Cs}$ source (Charbucinski et al., 1997, Asfahani, 1999). It is well known that the low activity tool is sensitive to changes in equivalent atomic number (Zeq) and is applicable for ore body delineation due to the difference in Zeq number between the host rock and the ore body. Therefore, five source to detector distances $(40,52,64,76$ and $88 \mathrm{~mm})$ have been tested to obtain the adapted configuration to be applied in the field. The optimization of the source-detector configuration will always be needed for each particular mineralization in order to obtain best results. In the present work, the regression equations for these five configurations in case of Barium and Cesium sources are given in order to describe the characteristics of each studied configuration. This is done in an attempt to select the best configuration for both Barium and Cesium sources. The application of this described spectrometric $\gamma-\gamma$ technique in the field of underground mining operations is also recommended. 


\section{Probe Configuration}

The low activity tool, for lead and zinc quantitative determination, was tested in this research. The tool was fabricated from aluminum of $3 \mathrm{~mm}$ thickness and its external diameter is $60 \mathrm{~mm}$, using $37 * 75 \mathrm{~mm} \mathrm{NaI}(\mathrm{TI})$ detector for detection of gamma radiation. The tool was centralized and used by ${ }^{133} \mathrm{Ba}$ and ${ }^{137} \mathrm{Cs}$ sources of $1.8 \mathrm{MBq}$ activity. The detector was shielded from the gamma ray source by $30 \mathrm{~mm}$ lead. An extra $\mathrm{Cd}+\mathrm{Cu}$ filter was placed between shielding and detector to further absorb unwanted X-rays. Because the gamma rays, originating from the ${ }^{133} \mathrm{Ba}$ source could not penetrate the lead shielding, an extra ${ }^{137} \mathrm{Cs}$ - source of $0.37 \mathrm{MBq}$ activity was added in order to provide a $662 \mathrm{KeV}$ gamma ray peak to stabilize the recorded backscattered gamma ray spectrum.

The backscattered gamma-ray spectra in this research were recorded in a stationary case, while, these measurements in a motion case are carried out with speed logging of 2-3 $\mathrm{m} / \mathrm{min}$ and stored directly on the hard disk of an IBM compatible PC for further analysis and interpretations.

\section{Principle of Lead Quantitative Determination}

Lead grade is determined from the $80 \mathrm{KeV} \mathrm{X}$-ray, which is prominent in the backscattered gamma ray spectrum. The gamma ray, having energy above 88 $\mathrm{KeV}$, can excite $\mathrm{X}$-ray from lead, producing an $80 \mathrm{KeV}$ peak. This peak is used to determine the $\mathrm{Pb}$ concentration, where the number of $\mathrm{X}$ - ray, recorded in this peak, is related to $\mathrm{Pb}$ concentration in the $\mathrm{Pb}-\mathrm{Zn}$ ore. However, a linear relationship can not be assumed between the lead concentration and the peak area due to distortion of the gamma ray flux by the bulk ore sample. This variation must be taken in consideration during data interpretation.

\section{Determination of Zinc Metal Equivalent (ZME)}

Zinc Metal Equivalent units provide a useful measure of the response of the probe to the total composition of the material. The utility of introducing this parameter is related to the fact that $\gamma-\gamma$ technique is not suitable to distinguish zinc from other heavy elements, such as $\mathrm{Pb}, \mathrm{Fe}$, and $\mathrm{Mn}$, associated with $\mathrm{Zn}-\mathrm{Pb}$ ores. $\mathrm{ZME}$ can be defined from the following equation:

$$
\mathrm{ZME}=\% \mathrm{Zn}+\% \mathrm{~Pb} * \mathrm{Ef}(\mathrm{Pb} / \mathrm{Zn})
$$

where $\mathrm{Ef}(\mathrm{Pb} / \mathrm{Zn})$ is a multiplier such that gamma radiation scattered and absorbed by a compound of a multi-heavy element medium and measured through a given spectral parameter results in the same value as that of the spectral parameter being measured in a mono heavy metal ore (e.g. $\mathrm{Zn}$ only). The value of $\mathrm{Ef}(\mathrm{Pb} /$ $\mathrm{Zn}$ ) has been determined as equals to 4 , for which the best root mean square (r.m.s.) value between \%ZME assayed and response tool has been obtained. 


\section{Laboratory Investigation}

\section{${ }^{133}$ Ba Source}

The $\gamma-\gamma$ backscattered measurements, carried out in the laboratory, had the aim of determining the probe configuration providing the best sensitivity for logging measurements of lead and zinc concentrations. The separations between source and bottom end of the detector in the probe were selected to be 40,52 , 64,76 and $88 \mathrm{~mm}$ using primary source of ${ }^{133} \mathrm{Ba}$ of $1.8 \mathrm{MBq}$. The detector is located at the top of the source. The measurements were carried out in 13 borehole geophysical models of $130 \mathrm{~mm}$-diameter. Each model holding a volume of about $200 \mathrm{~L}$ of crushed $\mathrm{Pb}-\mathrm{Zn}$ ore and the tool was centered in the hole through these models. The chemical composition of the 13 models is shown in Table 1.

TABLE 1. Chemical composition of the 13 geophysical models.

\begin{tabular}{|c|c|c|}
\hline Geophysical model & $\mathrm{Pb} \%$ & $\mathrm{Zn} \%$ \\
\hline 1 & 4.27 & 4.71 \\
\hline 2 & 3.83 & 4.32 \\
\hline 3 & 5.81 & 5.86 \\
\hline 4 & 0.52 & 0.52 \\
\hline 5 & 7.10 & 19.08 \\
\hline 6 & 5.02 & 6.03 \\
\hline 7 & 5.40 & 6.52 \\
\hline 8 & 5.06 & 6.42 \\
\hline 9 & 5.74 & 12.48 \\
\hline 10 & 7.87 & 9.40 \\
\hline 11 & 0.65 & 0.87 \\
\hline 12 & 7.77 & 9.47 \\
\hline 13 & 6.66 & 9.2 \\
\hline
\end{tabular}

Fig. 1(a) shows the spectra collected using the low activity 133Ba tool on three geophysical models (No 3, 4 and 10) having different quantities of lead (0.52, 5.81, 7.87\%), (Asfahani, 1999). The peak, which corresponds to the $662 \mathrm{KeV}$ gamma ray from ${ }^{137} \mathrm{Cs}$, is used to gain stabilization. It is clear from Fig. 1(b), that the low energy region of spectra shows a differentiation in intensity between these three models. The intensity of the backscattered spectrum is determined by both the density of the medium and its chemical composition. The chemical composition affects mostly this low energy region. The high-energy region carries the information about the density of the matrix surrounding the borehole (Borsaru et al., 1985). Fig. 2 presents low energy part of the spectra 


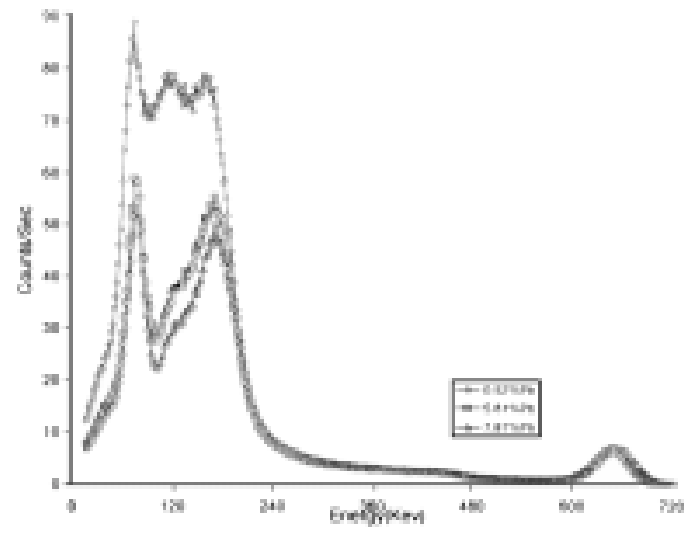

FIG. 1(a). Backscattered $\gamma-\gamma$ spectra collected using ${ }^{133} \mathrm{Ba}$ source for different quantities of $\mathrm{Pb}$ (0.52, 5.81 and $7.87 \%)$.

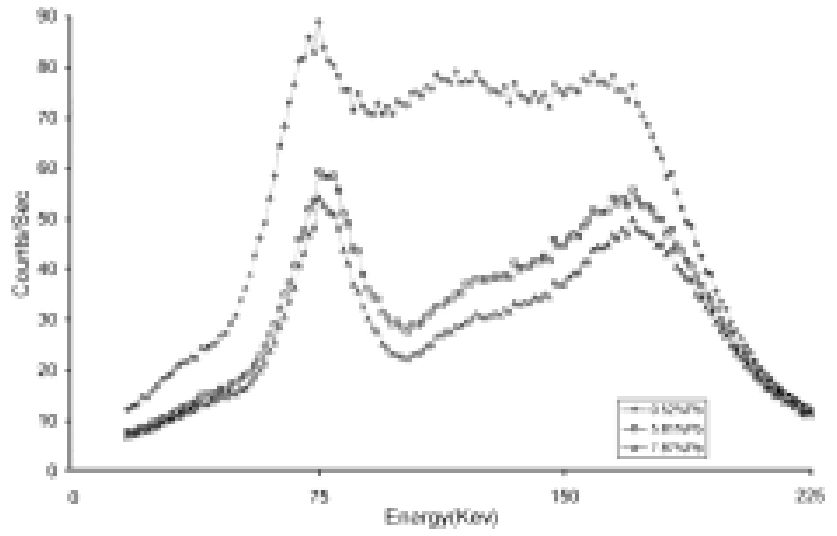

FIG. 1(b). Detailed spectra of Fig. 1(a) recorded in low energy regions.

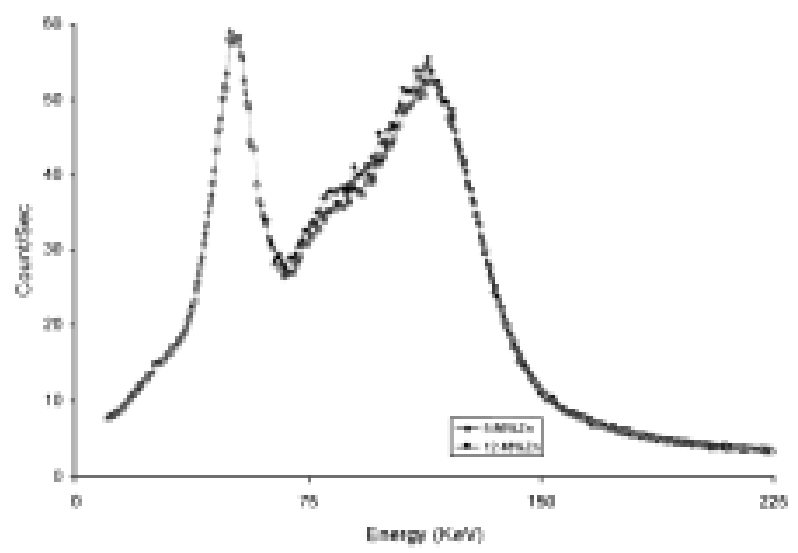

FIG. 2. Elargated spectra recorded in low energy regions and collected in two geophysical models of the same $\mathrm{Pb} \%$ but different quantities of $\mathrm{Zn} \%$ (5.86, $12.4 \%)$. 
recorded and collected in two geophysical models (No. 3 and 9), having approximately the same quantity of lead $(5.8 \%)$, but different quantity of zinc (5.86 and $12.48 \%$ respectively), (Asfahani, 1999).

Linear regression analysis was used to analyze and interpret the experimental data obtained from the 13 geophysical models. This regression was applied for the five probe configurations $(40,52,64,76$, and $88 \mathrm{~mm})$. The results of this regression analyses are summarized in Table 2 . The various regression analyses for each of the probe configuration gave high values of the correlation coefficient $(\mathrm{Rc}>0.95)$ between assayed $\mathrm{Pb}$ contents and the various spectral ratios based on spectral windows and $\mathrm{P}_{\mathrm{z}}$ parameters. $\mathrm{P}_{\mathrm{z}}$ is the ratio between count rate in two windows at high and low energies. The r.m.s. deviations between laboratory assays and the tool's prediction vary between 0.33 and 0.41 . These regression analyses gave also high values of the correlation coefficient $(\mathrm{Rc}>0.92)$ between assayed Zinc Metal Equivalent (ZME) and the various spectral and $\mathrm{P}_{\mathrm{z}}$ parameters considered. The r.m.s. deviations between laboratory assays and the tool's prediction vary between 2.3 and 2.88 .

TABLE 2. Regression analysis results for the five-tested probe configurations using ${ }^{133} \mathrm{Ba}$ source.

\begin{tabular}{|c|c|c|c|c|c|c|}
\hline \multirow{2}{*}{ S-D spacing } & \multicolumn{5}{|c|}{ 133Ba source } \\
\cline { 2 - 7 } & \multicolumn{3}{|c|}{$\% \mathrm{~Pb}$} & \multicolumn{3}{c|}{ \% ZME } \\
\cline { 2 - 7 } & r.m.s. & $\mathrm{Rc}$ & & r.m.s. & Rc & \\
\hline $40 \mathrm{~mm}$ & 0.41 & 0.96 & 2.3 & 2.88 & 0.949 & 13.47 \\
\hline $52 \mathrm{~mm}$ & 0.33 & 0.97 & 2.3 & 2.3 & 0.961 & 13.47 \\
\hline $64 \mathrm{~mm}$ & 0.39 & 0.96 & 2.3 & 2.6 & 0.94 & 13.47 \\
\hline $76 \mathrm{~mm}$ & 0.34 & 0.98 & 2.3 & 2.72 & 0.93 & 13.47 \\
\hline $88 \mathrm{~mm}$ & 0.34 & 0.98 & 2.3 & 2.78 & 0.94 & 13.47 \\
\hline
\end{tabular}

Fig. 3 shows cross-plots of calibration data between the chemical assay of $\mathrm{Pb}$ and the low activity ${ }^{133} \mathrm{Ba}$ tool prediction for the five probe configurations. The regression analysis generates the following equations:

$$
\begin{aligned}
& \text { [40 mm] } \% \mathrm{~Pb}=-0.02 \text { Roi3 + 2.66 Rat } 1-3.483 \\
& \text { [52 mm] } \% \mathrm{~Pb}=-0.024 \text { Roi2 + 13.377 Rat2 }-7.158 \\
& \text { [64 mm] } \% \mathrm{~Pb}=-0.0276 \text { Roi2 }+10.618 \text { Rat } 2-2.338 \\
& \text { [76 mm] } \% \mathrm{~Pb}=-0.0205 \text { Roi2 + 10.67 Rat2 }-5.97 \\
& {[88 \mathrm{~mm}] \quad \% \mathrm{~Pb}=-0.024 \text { Roi2 }+9.40 \text { Rat2 }-6.147}
\end{aligned}
$$

The meaning of the variables, used in these equations, is explained in Table 3. 


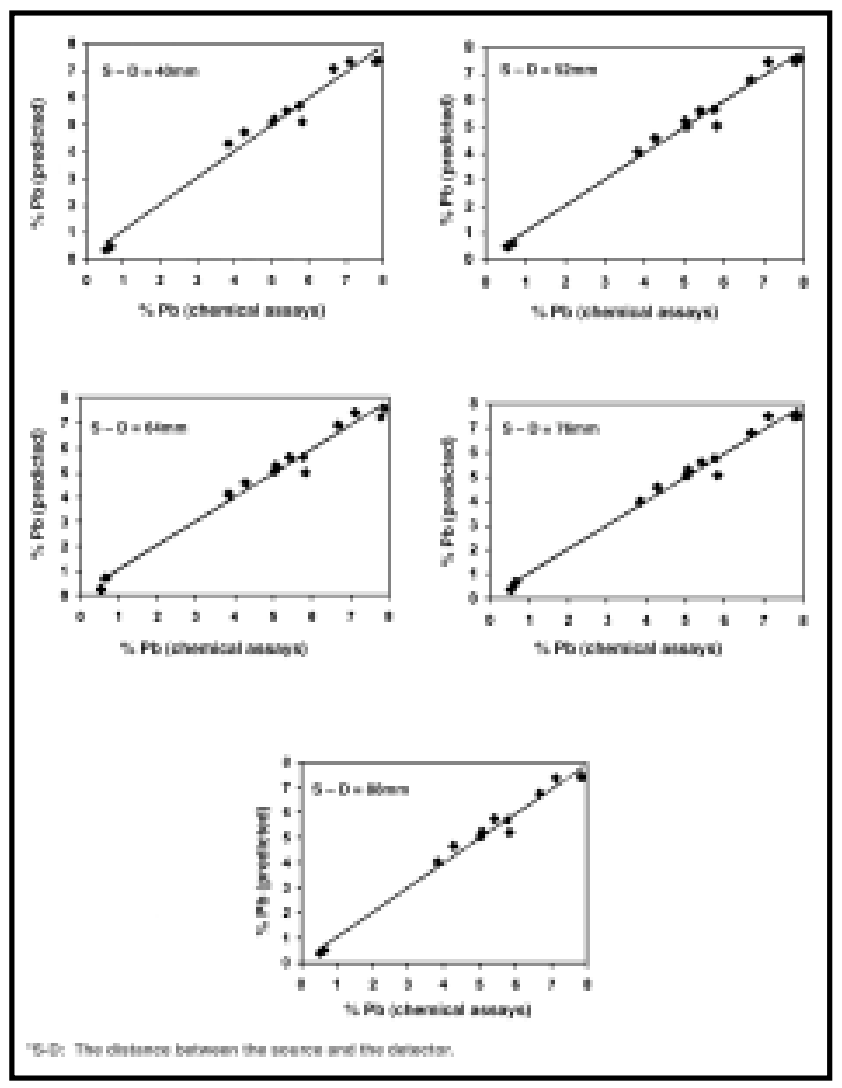

FIg. 3. Comparison of $\mathrm{Pb} \%$ determined by chemical analysis and ${ }^{133} \mathrm{Ba}$ tool prediction, for the five probe configurations.

TABLE 3. Variables used for $\mathrm{Pb}$ determination using ${ }^{133} \mathrm{Ba}$ source.

\begin{tabular}{|c|c|}
\hline Roi & Rat \\
\hline Roi2 $(52.5-108 \mathrm{KeV})^{*}$ & Rat1 $(51-100.5) /(97.5-105 \mathrm{KeV})$ \\
\hline Roi3 $(51-100.5 \mathrm{KeV})$ & Rat2 $(51-100.5) / 105-135(\mathrm{KeV})$ \\
\hline
\end{tabular}

${ }^{*}$ The count rate in the spectral window

The ratios in these equations take into account the variation of gamma-ray flux in the bulk sample and represent the normalization of the count rate of lead peak to the gamma-rays of energies just above the $\gamma$-ray peak.

Fig. 4 shows cross-plots of calibration data between chemical ZME and the low activity ${ }^{133} \mathrm{Ba}$ tool predictions for the five configurations. The regression analysis gives the following equations: 


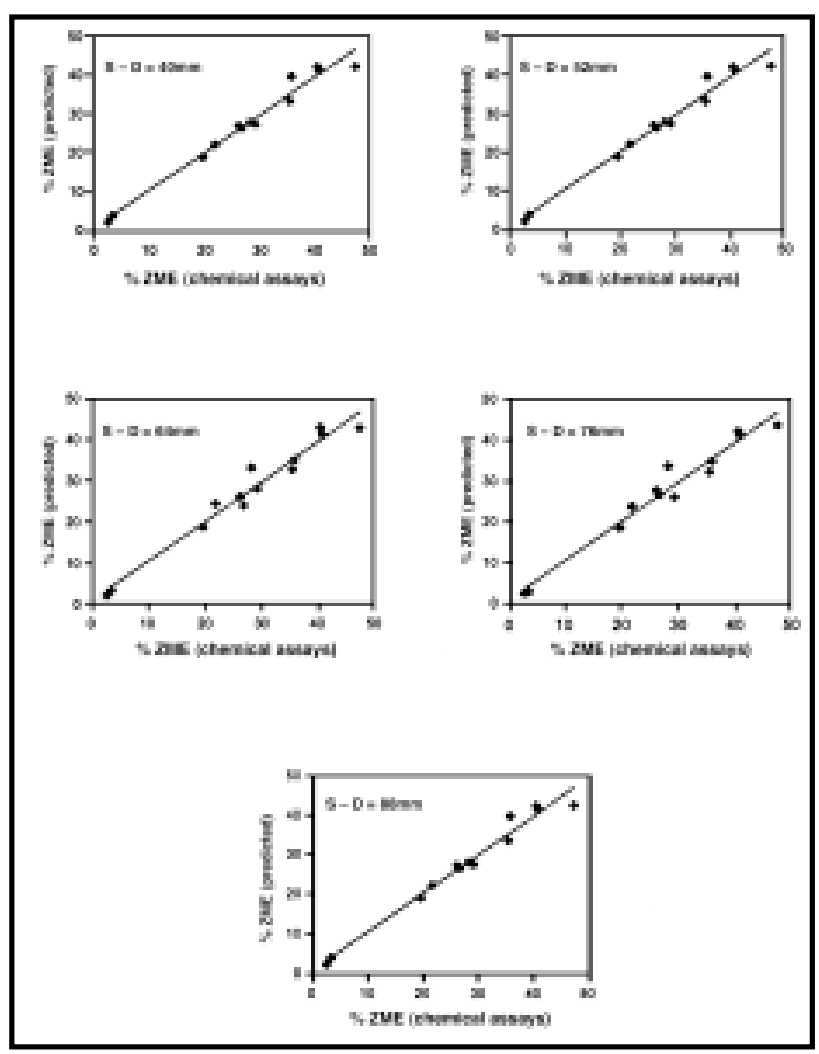

FIG. 4. Comparison of ZME\% determined by chemical analysis and ${ }^{133} \mathrm{Ba}$ tool prediction, for the five probe configurations.

$$
\begin{array}{ll}
{[40 \mathrm{~mm}]} & \% \text { ZME }=-0.062 \text { Roi6 }-102.33 \text { Rat } 2+270 \\
{[52 \mathrm{~mm}]} & \% \text { ZME }=-0.041 \text { Roi3 }+1827.73 \text { Rat3 }-182.28 \\
{[64 \mathrm{~mm}]} & \% \text { ZME }=-0.094 \text { Roi6 }-98.28 \text { Rat } 1+295.59 \\
{[76 \mathrm{~mm}]} & \% \text { ZME }=-0.011 \text { Roi6 }-121.37 \text { Rat } 1+319.92 \\
{[88 \mathrm{~mm}]} & \% \text { ZME }=-0.3 \text { Roi7 }-121.05 \text { Rat } 8+309.1
\end{array}
$$

The meaning of the variables, used in these equations, is explained in Table 4.

TABLE 4. Variables used for ZME determination using ${ }^{133} \mathrm{Ba}$ source.

\begin{tabular}{|c|c|}
\hline Rai & Rat \\
\hline Roi6 $(135-180 \mathrm{KeV})$ & Rat2 $(225-300) /(75-105 \mathrm{KeV})$ \\
\hline Roi3 $(150-180 \mathrm{KeV})$ & Rat3 $(225-300) /(45-120 \mathrm{KeV})$ \\
\hline Roi7 $(180-232.5 \mathrm{KeV})$ & Rat1 $(135-210) /(60-105 \mathrm{KeV})$ \\
\hline & Rat8 $(135-180) /(51-100.5 \mathrm{KeV})$ \\
\hline
\end{tabular}




\section{${ }^{137}$ Cs Source}

The five probe configurations were also tested, using primary source of ${ }^{137} \mathrm{Cs}$ of $1.8 \mathrm{MBq}$. Fig. 5 shows the spectra collected on three geophysical models (No. 3,4 and 10), (Asfahani, 1999). The peak, which corresponds to the 662 $\mathrm{KeV}$ gamma ray, is used for gain stabilization.

Linear regression analysis was carried out in order to interpret the experimental data obtained from the 13 geophysical models. The results of this regression analysis for the five probe configurations are summarized in Table 5.

The regression analysis for each of the probe configuration indicates high values of the correlation coefficient $(\mathrm{Rc}>0.97)$ between assayed $\mathrm{Pb}$ contents and the various spectral ratios based on spectral windows and $\mathrm{P}_{\mathrm{Z}}$ parameters.

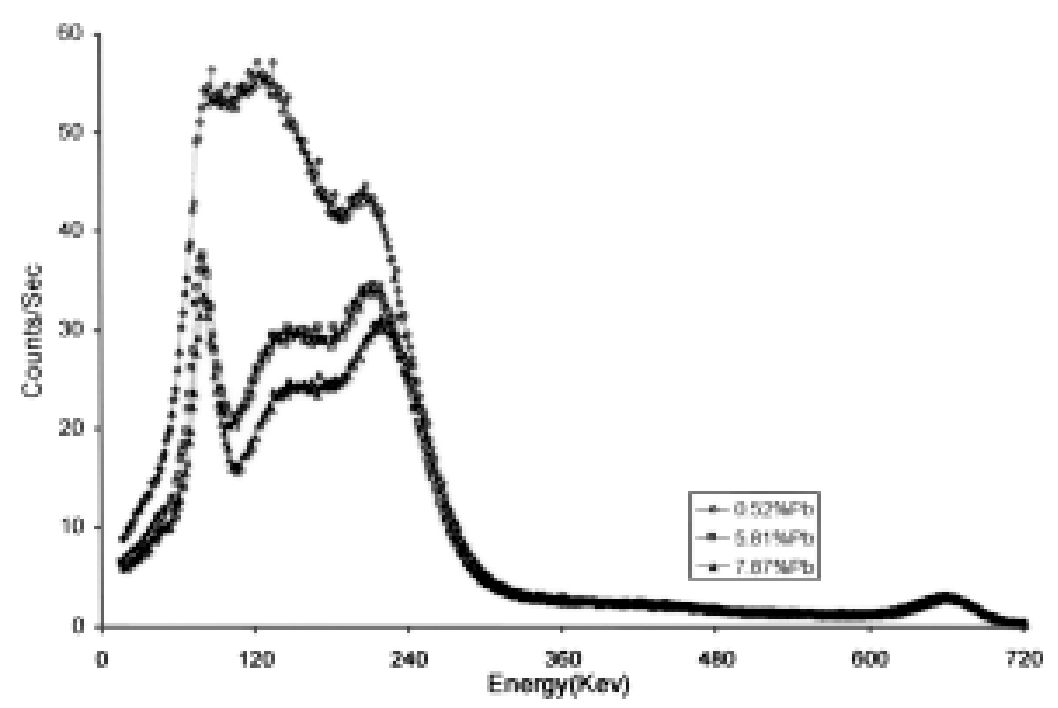

FIG. 5. Backscattered $\gamma-\gamma$ spectra collected using ${ }^{137} \mathrm{Cs}$ source for different quantities of $\mathrm{Pb} \%$ $(0.52,5.81,7.87 \%)$.

The r.m.s. between laboratory assay and the tool prediction varies between 0.29 and 0.37 percent lead. This regression analysis indicates also high values of the correlation coefficient ( $\mathrm{Rc}>0.89$ ) between assayed $\mathrm{ZME}$ and the various spectral parameters considered in the calibration equations. The r.m.s. deviation between laboratory assays and the tool prediction varies between 2.20 and 2.83 percent ZME.

Fig. 6 presents cross-plots of calibration data between the chemical assay of $\mathrm{Pb}$ and the low activity ${ }^{137} \mathrm{Cs}$ tool prediction for the five probe configurations. The regression analysis gives the following calibration equations: 


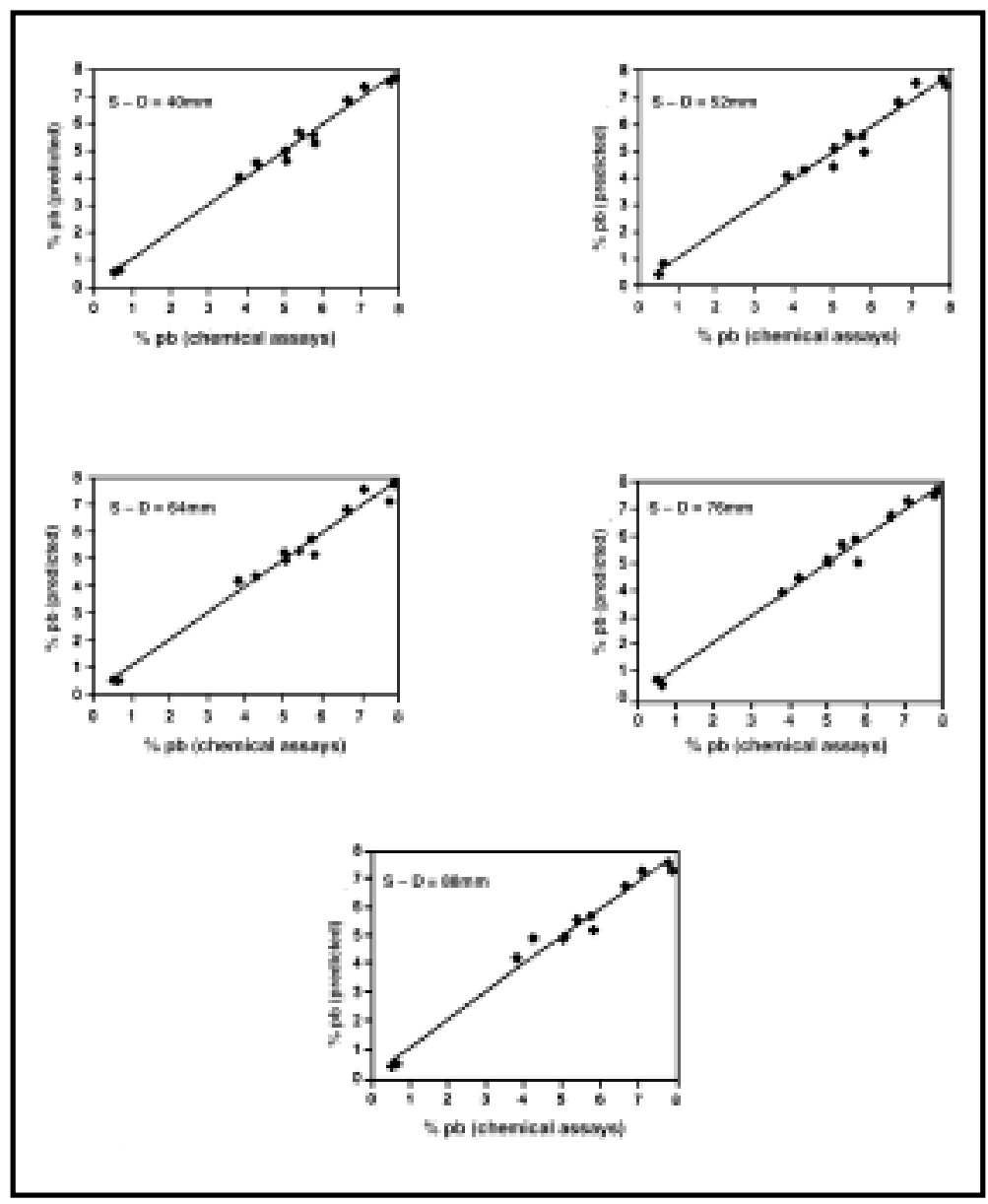

FIG. 6. Comparison of $\mathrm{Pb} \%$ determined by chemical analysis and ${ }^{137} \mathrm{Cs}$ tool prediction, for the five probe configurations.

$$
\begin{array}{ll}
{[40 \mathrm{~mm}]} & \% \mathrm{~Pb}=-0.033 \text { Roi } 2+19.07 \text { Rat2 }-13.36 \\
{[52 \mathrm{~mm}]} & \% \mathrm{~Pb}=-0.0318 \text { Roi } 2+15.87 \text { Rat2 }-9.70 \\
{[64 \mathrm{~mm}]} & \% \mathrm{~Pb}=-0.0459 \text { Roi } 2+13.35 \text { Rat2 }-2.94 \\
{[76 \mathrm{~mm}]} & \% \mathrm{~Pb}=-0.024 \text { Roi } 2+13.66 \text { Rat }-10.52 \\
{[88 \mathrm{~mm}]} & \% \mathrm{~Pb}=-0.0278 \text { Roi } 2+12.65 \text { Rat } 2-9.04
\end{array}
$$

The significance of the Roi2 and Rat2, used in these equations, is the same as presented in Table 5. 
TABLE 5. Regression analysis results for the five-tested probe configurations using ${ }^{137} \mathrm{Cs}$ source.

\begin{tabular}{|c|c|c|c|c|c|c|}
\hline \multirow{2}{*}{ S-D Spacing } & \multicolumn{6}{|c|}{${ }^{133}$ Cs source } \\
\cline { 2 - 7 } & \multicolumn{3}{|c|}{$\% \mathrm{~Pb}$} & \multicolumn{3}{c|}{$\%$ ZME } \\
\cline { 2 - 7 } & r.m.s. & $\mathrm{Rc}$ & $\sigma$ & r.m.s. & Rc & $\sigma$ \\
\hline $40 \mathrm{~mm}$ & 0.29 & 0.987 & 2.33 & 2.48 & 0.95 & 13.46 \\
\hline $52 \mathrm{~mm}$ & 0.35 & 0.98 & 2.33 & 2.73 & 0.9 & 13.46 \\
\hline $64 \mathrm{~mm}$ & 0.36 & 0.971 & 2.33 & 2.2 & 0.95 & 13.46 \\
\hline $76 \mathrm{~mm}$ & 0.306 & 0.988 & 2.33 & 2.83 & 0.94 & 13.46 \\
\hline $88 \mathrm{~mm}$ & 0.377 & 0.98 & 2.33 & 2.79 & 0.89 & 13.46 \\
\hline
\end{tabular}

Fig. 7 shows cross-plots of calibration data between chemical assay of ZME and the low activity ${ }^{137} \mathrm{Cs}$ tool for the five probe configurations. The calibration equations for ZME prediction have the following forms:

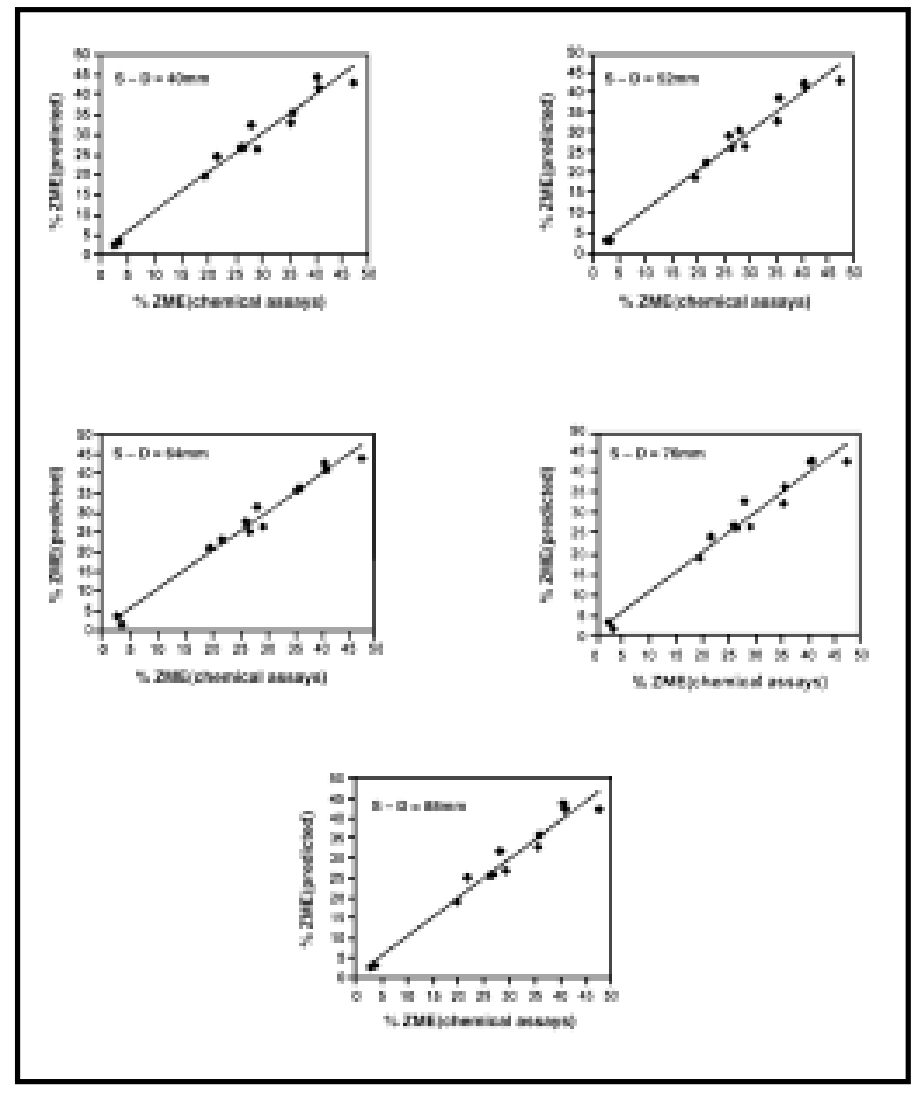

FIG. 7. Comparison of ZME\% determined by chemical analysis and ${ }^{137} \mathrm{Cs}$ tool prediction, for the five probe configurations. 


$$
\begin{array}{lll}
{[40 \mathrm{~mm}]} & \% \mathrm{ZME}=0.083 \text { Roi14 }+238.14 \text { Rat } 7-231.35 & {[17]} \\
{[52 \mathrm{~mm}]} & \% \mathrm{ZME}=-0.478 \text { Roi1 }-189.84 \text { Rat8 }+333.21 & {[18]} \\
{[64 \mathrm{~mm}]} & \% \mathrm{ZME}=-0.21 \text { Roi7 }-78.26 \text { Rat5 }+414.17 & {[19]} \\
{[76 \mathrm{~mm}]} & \% \mathrm{ZME}=-0.082 \text { Roi6 }-138.27 \text { Rat } 8+235.72 & {[20]} \\
{[88 \mathrm{~mm}]} & \% \mathrm{ZME}=-0.466 \text { Roi1 } 1-241.16 \text { Rat } 8+341.37
\end{array}
$$

The explanation of the variables, used in these equations, is shown in Table 6.

TABLE 6. Variables used for ZME determination using ${ }^{137}$ Cs source.

\begin{tabular}{|l|l|}
\hline \multicolumn{1}{|c|}{ Roi } & Rat \\
\hline Roi14 $(75-105 \mathrm{KeV})$ & Rat7 $(190.5-210) /(105-142.5 \mathrm{KeV})$ \\
\hline Roi1 $(30-52.5 \mathrm{KeV})$ & Rat8 $(135-180) /(51-100.5 \mathrm{KeV})$ \\
\hline Roi7 $(180-232.5 \mathrm{KeV})$ & Rat5 $(165-262.5) /(45-105 \mathrm{KeV})$ \\
\hline Roi6 $(135-180 \mathrm{KeV})$ & \\
\hline Roi11 $(37.5-60 \mathrm{KeV})$ & \\
\hline
\end{tabular}

\section{Results and Discussion}

The comparison between the backscattered $\gamma-\gamma$ results, obtained by using ${ }^{133} \mathrm{Ba}$ and ${ }^{137} \mathrm{Cs}$ sources, can be enumerated as follows:

1. It is observed that changing the separation between the source and detector from $40 \mathrm{~mm}$ to $88 \mathrm{~mm}$ does not have a big influence on the recorded spectra.

2. It was found from Table 2 that the $52 \mathrm{~mm}$ configuration is considered to be the best that is adapted for both $\mathrm{Pb}$ and ZME quantitative determinations (Asfahani, 1999). For that configuration, the smallest r.m.s and highest Rc were obtained, using very low radioactivity of $133 \mathrm{Ba}$ source. The r.m.s. deviations between $\gamma-\gamma$ prediction and laboratory assay was $0.33 \% \mathrm{~Pb}$. This r.m.s represents a measure of the accuracy in determining the average grade based on the laboratory chemical assay of the core sample. The standard deviation $(\sigma)$ for the population were $2.3 \% \mathrm{~Pb}$ and $13.4 \% \mathrm{ZME}$. In general the standard deviation $\sigma$ is defined as:

$$
\sigma=\sqrt{\frac{\sum_{\mathrm{i}=1}^{\mathrm{n}}(\mathrm{xi}-\overline{\mathrm{x}})^{2}}{\mathrm{n}}}
$$

where, $x i$ are the core values chosen in the calibration equation, $\bar{x}$ is the mean and $\mathrm{n}$ is the number of samples. 
The r.m.s. deviation between laboratory assay and the tool prediction was $2.3 \% \mathrm{ZME}$. The two variables, used in equation 8 , have physical meanings. Rat3 considered as $\mathrm{P}_{\mathrm{Z}}$ ratio is related to the chemical composition of $\mathrm{Zn}$ e.g. \%ZME, while Roi3 is almost related to the density of ore material.

3. It is evident from Table 5 that $64 \mathrm{~mm}$ probe configuration is considered as compromise for both $\mathrm{Pb}$ and $\mathrm{ZME}$ prediction using very low radioactivity of ${ }^{137}$ Cs source, (Asfahani, 1999). For this configuration, the r.m.s. deviation between $\gamma-\gamma$ prediction and laboratory assay was $0.36 \% \mathrm{~Pb}$. The r.m.s deviation between laboratory assay and the tool prediction was $2.2 \%$ ZME.

The standard deviation for the population $\sigma$ was $2.33 \%$ for $\mathrm{Pb}$. The standard deviation for the population $\sigma$ was $13.465 \%$ for ZME. The two variables used in equation 19 have the same physical meaning as that used in equation 8 .

4. The spectral parameters, used in regression analysis for both ${ }^{133} \mathrm{Ba}$ and ${ }^{137}$ Cs sources, are statistically significant and have physical meaning.

5. The variables, used in the calibration equations for $\mathrm{Pb}$ prediction (Roi2, Rat2) are the same for ${ }^{133} \mathrm{Ba}$ and ${ }^{137} \mathrm{Cs}$ sources.

6. The sensitivity of tool logging, using both ${ }^{133} \mathrm{Ba}$ and ${ }^{137} \mathrm{Cs}$ sources, were also tested and compared. The sensitivity $\mathrm{S}$ is defined as :

$$
\mathrm{S}=\frac{\frac{\mathrm{Y} 2-\mathrm{Y} 1}{\overline{\mathrm{Y}}}}{\frac{\mathrm{X} 2-\mathrm{X} 1}{\overline{\mathrm{X}}}}
$$

where Y1, Y2 : are the predicted values for two data points 1,2.

$\overline{\mathrm{Y}} \quad$ : the predicted average of 13 data points.

$\mathrm{X} 1, \mathrm{X} 2:$ are the chemical values for two data points 1,2 .

$\overline{\mathrm{X}} \quad$ : the chemical average of 13 data points.

The absolute and relative average errors $\overline{\mathrm{E}}, \overline{\mathrm{E}}$ for the determination of a given $\mathrm{Vk}$, are calculated from the following formulae:

$$
\begin{aligned}
& \overline{\mathrm{E}}=\frac{\sum_{\mathrm{i}=1}^{\mathrm{n}}\left[\mathrm{V}_{\mathrm{k}, \mathrm{i}}^{\mathrm{c}}-\mathrm{V}_{\mathrm{k}, \mathrm{i}}^{\mathrm{p}}\right]}{\mathrm{n}} \\
& \overline{\mathrm{E}} \mathrm{r}=\frac{\sum_{\mathrm{i}=1}^{\mathrm{n}} \frac{\left[\mathrm{V}_{\mathrm{k}, \mathrm{i}}^{\mathrm{c}}-\mathrm{V}_{\mathrm{k}, \mathrm{i}}^{\mathrm{p}}\right]}{\mathrm{V}_{\mathrm{k}, \mathrm{i}}^{\mathrm{c}}}}{\mathrm{n}}
\end{aligned}
$$


where: $\mathrm{V}_{\mathrm{k}, \mathrm{i}}^{\mathrm{c}}$ and $\mathrm{V}_{\mathrm{k}, \mathrm{i}}^{\mathrm{p}}=\mathrm{i}^{\text {th }}$ value of the chemical and predicted $\mathrm{k}^{\text {th }}$ parameter $\mathrm{Vk}$. n: number of data points.

The values of $\overline{\mathrm{E}}$ and $\overline{\mathrm{E}}$ r were calculated from 13 data points for all the studied configurations.

Results of S, $\overline{\mathrm{E}}$ and $\overline{\mathrm{E}}$ r are tabulated in Table 7 . One can notice that there is a slight difference in sensitivity when ${ }^{133} \mathrm{Ba}$ source is used compared to ${ }^{137} \mathrm{Cs}$ source. However, if we compare this sensitivity in the case of $52 \mathrm{~mm}$-probe configuration for both ${ }^{133} \mathrm{Ba}$ and ${ }^{137} \mathrm{Cs}$ sources, we notice that the sensitivity of $133 \mathrm{Ba}$ source is slightly better than that of ${ }^{137} \mathrm{Cs}$ one.

TABLE 7. Sensitivity of tool logging using ${ }^{137} \mathrm{Cs}$ and ${ }^{133} \mathrm{Ba}$ source.

\begin{tabular}{|c|c|c|c|c|c|c|c|c|c|c|c|c|}
\hline \multirow{2}{*}{ S-D Spacing } & \multicolumn{5}{|c|}{${ }^{133} \mathrm{Ba}$ source } & \multicolumn{5}{c|}{${ }^{137}$ Cs source } \\
\cline { 2 - 16 } & $\mathrm{S}$ & $\mathrm{E}(\% \mathrm{pb})$ & $\operatorname{Er}(\%)$ & $\mathrm{S}$ & $\mathrm{E}(\% \mathrm{ZME})$ & $\operatorname{Er}(\%)$ & $\mathrm{S}$ & $\mathrm{E}(\% \mathrm{pb})$ & $\operatorname{Er}(\%)$ & $\mathrm{S}$ & $\mathrm{E}(\% \mathrm{ZME})$ & $\operatorname{Er}(\%)$ \\
\hline $40 \mathrm{~mm}$ & 0.764 & 0.30 & 8.6 & 0.954 & 2.014 & 9.2 & 0.917 & 0.212 & 4.3 & 1.07 & 1.781 & 7.6 \\
\hline $52 \mathrm{~mm}$ & 0.876 & 0.230 & 5.2 & 1.057 & 1.392 & 5.9 & 0.837 & 0.269 & 7.9 & 1.04 & 1.742 & 5.4 \\
\hline $64 \mathrm{~mm}$ & 0.861 & 0.29 & 9.3 & 1.069 & 1.666 & 6.6 & 0.881 & 0.241 & 5.8 & 0.924 & 1.59 & 11.5 \\
\hline $76 \mathrm{~mm}$ & 0.872 & 0.236 & 6.3 & 1.062 & 1.805 & 7.0 & 0.944 & 0.204 & 7.2 & 1.1 & 1.99 & 11.6 \\
\hline $88 \mathrm{~mm}$ & 0.84 & 0.249 & 7.3 & 1.050 & 1.785 & 6.5 & 0.770 & 0.257 & 7.7 & 1.09 & 1.850 & 6.7 \\
\hline
\end{tabular}

7. Taking into account the r.m.s. Rc, and the sensitivity obtained using ${ }^{133} \mathrm{Ba}$ and ${ }^{137} \mathrm{Cs}$ sources for the five probe configurations, it appears that the performances of tools with ${ }^{133} \mathrm{Ba}$ and ${ }^{137} \mathrm{Cs}$ sources are comparable.

8 . The fact that the tool can predict ZME suggests that there is a potential for the quantitative determination of the $\% \mathrm{Zn}$ content in the samples, provided that supplementary physical techniques are used to assess the Fe content while the $\mathrm{Pb}$ content could be readily determined concurrently from spectral response at the $\mathrm{Pb} \mathrm{X}$-ray peak.

\section{Summary and Conclusions}

The present work demonstrates that the low activity logging tools with the configuration described in this paper can be successfully employed in the metalliferous mining industry for the determination of $\mathrm{Pb}$ and $\mathrm{ZME}$ in bulk $\mathrm{Pb}-\mathrm{Zn}$ ore samples. The activities of the gamma-ray sources used with the present tools are so low that they do not require special shielding. This makes the tools suitable 
for underground mining operations in horizontal borehole or for portable logging systems particularly where weight is an important consideration. The tool configuration was chosen so that it enhances the contribution of the low energy region in the backscattered $\gamma$-ray spectrum.

Experimental results show that the optimum configuration is $52 \mathrm{~mm}$ sourcedetector spacing when ${ }^{133} \mathrm{Ba}$ source is used, and is $64 \mathrm{~mm}$ when ${ }^{137} \mathrm{Cs}$ source is applied.

The low activity ${ }^{137} \mathrm{Cs}$ does not need an extra source for spectrum gain stabilization, where the same source is used for both primary sources of radiation and gain stabilization. In addition, ${ }^{137} \mathrm{Cs}$ source is characterized by longer halflife and greater penetration effect of its gamma radiation.

The low activity ${ }^{133} \mathrm{Ba}$ source however necessitates an additional ${ }^{137} \mathrm{Cs}$ microsource for gain stabilization.

This technique has considerable potential for the determination of $\mathrm{Zn}$ grade in special cases when the concentration of elements with high atomic number like $\mathrm{Fe}, \mathrm{Mn}, \mathrm{Cu}$ is constant or can be estimated by other methods

\section{Acknowledgements}

The author would like to thank Prof. I. Othman general director of Syrian atomic energy commission for his serious encouragement. He would like to thank also the International Atomic Energy Agency (IAEA) for funding his research fellowship, which enabled him to carry out the experimental work reported in this paper. The research was carried out at the Queensland Center for Advanced Technologies, Commonwealth Scientific and Industrial Research Organization, Brisbane, Australia. The author is also grateful for considerable help he received at CSIRO and wishes to thank Dr M.Borsaru and Dr J. Charbucinski, Exploration and Mining Division, for the many suggestions and useful discussions initiated during his stay there. Special thanks are also to the referees of FES-KAU for their remarks and suggestions aiming at improving the quality of this paper.

\section{References}

Asfahani, J. (1999) Optimization of spectrometric gamma-gamma probe configuration using very low radioactivity sources for lead and zinc grade determination in borehole logging. Applied Radiation and Isotopes. 51: 449-459.

Borsaru, M., Charbucinski, J., Eisler, P.L. and Youl, S. F. (1985) Determination of ash content in coal by borehole logging in dry boreholes using gamma-gamma methods. Geoexploration 23: 503-518.

Borsaru, M. and Ceravolo, C. (1994) A low activity spectrometric gamma-gamma borehole logging tool for the coal industry. Nucl. Geophys. 8: 343-350. 
Borsaru, M., Ceravolo, C. and Tchen, T. (1995) The application of the low activity borehole logging tools to the iron mining industry. Nucl. Geophys. 9: 55-62.

Charbucinski, J. (1993) The 'ZERO PROBE' - Low radioactivity borehole logging tool. In Transactions of the 1993 Nuclear Science Symposium, San Francisco, USA, 2: 855.

Charbucinski, J., Ceravolo ,C. and Tchen, T. (1996) Ultra- low activity spectrometric probe for the coal mining industry. Journal of Radiochemical and Nuclear Chemistry, Articles, 206 (2): 311-319.

Charbucinski, J., Borsaru, M. and Gladwin, M. (1997) Ultra-Low radiation intensity spectrometric probe for ore body delineation and grade control of $\mathrm{Pb} . \mathrm{ZN}$ ore. Fourth Decennial International Conference Ore Mineral exploration, September 14-18, 1997, Toronto, Canada. 


\title{
سابرة غاما-غاما الطيفية البئرية للصناعة التعدينية

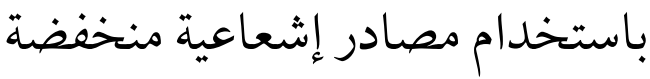

\author{
جمال عبده أصفهاني \\ هيئة الطاقـة الذريـة ، قسم الجيولوجيا

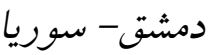

المستخلص . طبقت تقانة غاما-غاما الطيفية البئرية بشدات إشعاعية

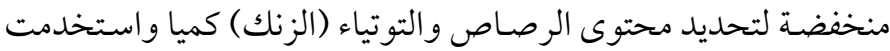

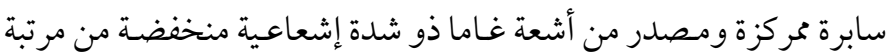

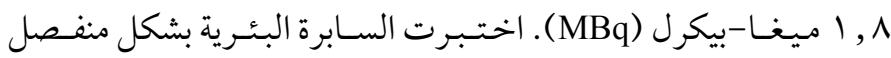

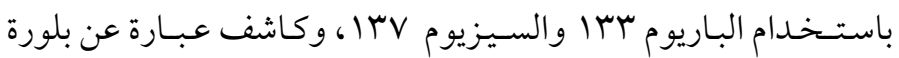

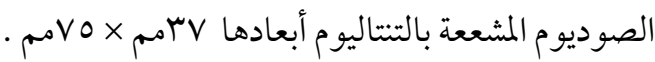

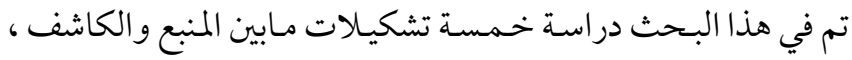

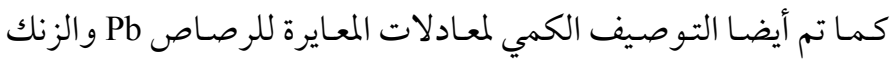

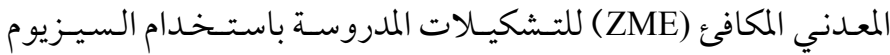

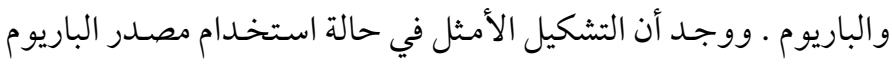

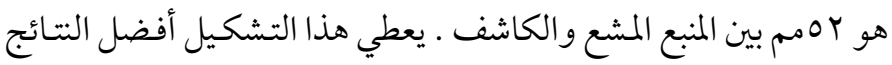

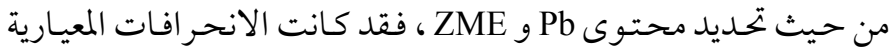

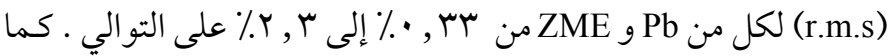

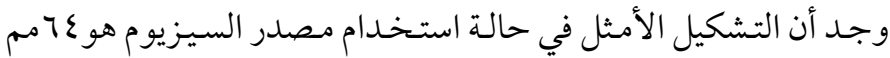

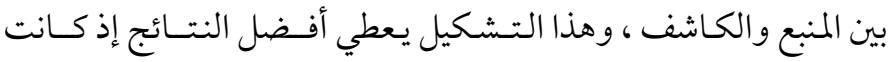

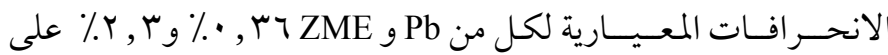

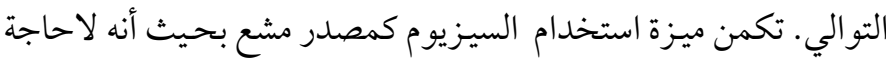

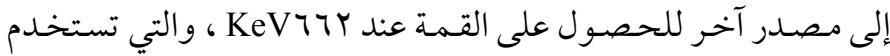

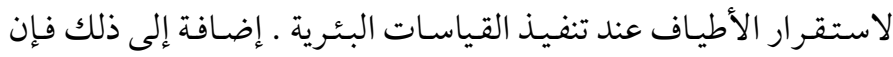

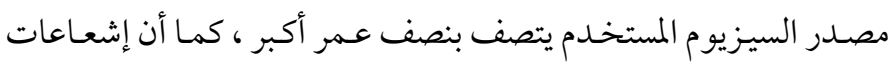
غاما الصادرة عنه تتميز بعمق اختراق أكبر . في حين يتطلب استخدام المبام 


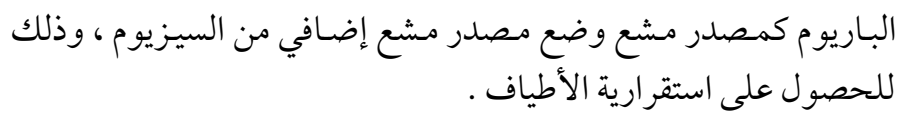

تعتبر السابرة المستخدمة حساسة تجاه تغيرات العدد الذري Zeq للمواد

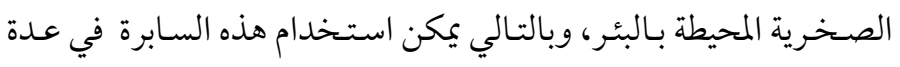

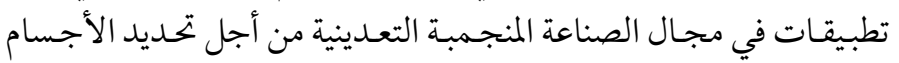

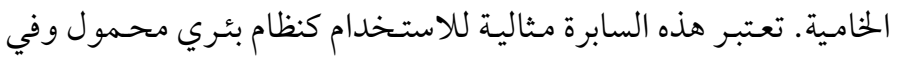

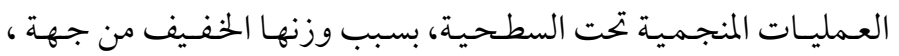

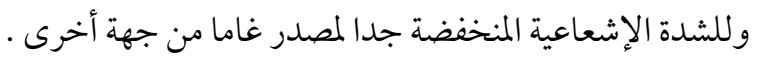

